\title{
INTERNAL POISONING FROM RHUS
}

\author{
JAMES B. MCNAIR \\ WASHINGTON, D. C.
}

ETIOLOGY

Most cases of internal poisoning by rhus have been caused by chewing the leaves of the plants and swallowing the juice in order to attain immunity to the poison. One of these cases terminated fatally (Alumbaugh, ${ }^{1}$ 1903). Dakin ${ }^{2}$ (1829) aptly commented on this procedure nearly a century ago:

Some good meaning, mystical, marvellous physicians, or favored ladies with knowledge inherent, say the bane will prove the best antidote, and hence advise the forbidden leaves to be eaten, both as a preventive and cure to the external disease. I have known the experiment tried, which resulted in an eruption, swelling, redness and intolerable itching, around the verge of the anus.

In 1907 , Conner ${ }^{3}$ reported one case caused by thoughtless chewing of a tender shoot of Rhus toxicodendron. Two cases are recorded in which children were poisoned by eating the fruit of Rhus toxicodendron (Moorman ${ }^{4}$ 1866). Root infusions were cited as a cause by French ${ }^{5}$ in 1903.

In internal rhus poisoning the amount of poison ingested is generally larger than in rhus dermatitis. There is also a possibility of other poisons than that which is the principal cause of dermatitis being absorbed from the plant.

The unripe fruits of Rhus toxicodendron and Rhus diversiloba produce dermatitis, but when fully ripe they do not cause dermatitis (McNair, ${ }^{6}$ 1917). The latter fact does not prove that the fruit is not poisonous when swallowed.

The fruit of Rhus coriara, a plant listed among the nondermatitisproducing rhus, will produce severe poisoning when swallowed (Esca-

1. Alumbaugh, W. E.: Med. World 21:176, 1903.

2. Dakin, R.: Remarks on the Cutaneous Affection Produced by Certain Poisonous Vegetables, Am. J. M. Sc. 4:98, 1829.

3. Conner, J. J.: Poisoning by Rhus Toxicodendron, J. Dermat. 11:368, 1907.

4. Moorman, J. W.: Poisoning by Eating the Fruit of Rhus Toxicodendron. Am. J. M. Sc. 51:560, 1866.

5. French, J. M.: Rhus Toxicodendron and Rhus Poisoning, Merck's Arch. 5:223, 359, 1903.

6. McNair, James B.: Fats from Rhus Diversiloba and Rhus Laurina. Botanical Gaz. 64:330, 1917. 
fet, ${ }^{7}$ 1847). The symptoms of children who had swallowed the seeds were similar to those cited in the cases of the two children who ate the fruit of Rhus toxicodendron reported by Moorman. In cases of poisoning caused by both these fruits the patients became drowsy and stupid and in a short time vomited partially digested fruit and fluid the color of wine. Convulsions followed.

Orfila, ${ }^{8}$ in 1866 , carried on a series of experiments on dogs with an aqueous extract of Rhus radicans. In some cases fatal results followed the ingestion of the extract, its injection into the jugular vein, or its application to a wound in the leg. The application of the extract to the cellular tissue on the back of a dog produced no "remarkable phenomena." The principal irritant of Rhus radicans is practically insoluble in water. The poison in the aqueous extract may have been tannin.

COURSE OF INTERNAL RHUS POISCNING

The features of internal rhus poisoning which are similar to those of rhus dermatitis are the shortness of its course and, typically, its differentiation into stages. The following stages in their proper sequence are generally recognized:

Stage of Infection.-This stage covers the period of time required by the poison to enter the outer surface of the mucous membrane and lining tissues in the mouth, throat and alimentary tract.

The Stage of Latency.-This stage covers the period of time in which the poison continues to enter the tissues up to the point of the production of symptoms. In a case in which poisoning occurred through the inhalation of smoke from burning rhus an irritation of the throat was immediately noticed (Seabrook, ${ }^{9} 1891$ ). In the cases of two children, one 6 and the other 8 years of age, who had eaten fruit of Rhus toxicodendron, symptoms of drowsiness appeared in a few hours (Moorman, 1866). In a case in which a young shoot of Rhus toxicodendron had been thoughtlessly chewed, symptoms of burning and itching of the lips and mouth were evident in about twenty-four hours (Conner, 1907). This and other evidence at hand proves that the symptoms of internal rhus poisoning become evident in a shorter length of time than in the average cases of external poisoning. The stage of latency, therefore, is an appreciably limited one, and its duration is a matter of a few hours at most when a considerable quantity

7. Escafet: De l'action toxique des baies du Rhus coriaria. Sumac des corroyeurs. Empoisonnements avec terminaisons funeste, J. de chim. méd. 3: $197,1847$.

8. Orfila, A. J. B.: Traité de toxicologie 2:132, 1866.

9. Seabrook, H. H.: A Peculiar Case of Poisoning, New York M. J. 54: $51,1891$. 
of poison has been ingested. During the time of ripening the fruits of Rhus diversiloba and Rhus toxicodendron contain an increasing amount of fat which has a maximum of about 20 per cent. ( $\mathrm{McNair}$, 1917 ) in the mesocarp. As the irritant poison is soluble in this fat, the fat may aid in the absorption of the poison. Fat absorption, however, is mainly a function of the intestines, whereas the poison produces stomatitis and gastritis, as well as enteritis.

Stage of Prodromes.-In this stage vague symptoms appear, such as headache, lassitude and possibly some irritation about the point of entrance of the poison. These prodromal symptoms are usually of brief duration; the duration depends on the same general factors that are indicated in the preceding stage. In a case of poisoning by the inhalation of smoke from burning rhus, irritation of the throat and general malaise occurred within a day after exposure. In a case of poisoning, probably caused by rhus smoke coming through an open car window, a sensation similar to sunburn was noticed in about twentyfour hours. Symptoms developed in a case of stomatitis in about the same length of time.

Stage of Invasion.-In this stage the symptoms characteristic of the disease make themselves manifest. As in rhus dermatitis, two types are recognized, namely, a frank or sudden invasion and an insidious or gradual invasion. The former is, doubtless, due to a sudden and severe intoxication, while the latter is due to a more gradual action. When the frank invasion occurs, naturally this stage is well separated from the prodromal, but they gradually merge during the insidious invasion. One of several factors may account for a frank invasion: 1. Poison swallowed in a large amount comes in contact with a large surface. Although it may be slowly absorbed, much is absorbed at the same time. 2. Some very sudden cause may be operative in reducing the vitality of the person, so that a given volume of poison may have an extreme and sudden effect. 3. The poison may have accumulated in a given focus owing to defective drainage, and then, by a sudden discharge of the poison into the system, a large quantity may be absorbed.

Primary Effect.-The primary effect of poisoning in this stage is to stimulate one or more functions of the system, while the secondary or final effect is to depress or pervert such functions subsequent to the production of degenerative and necrotic changes. Practically every function may be affected and metabolic and circulatory activity may receive an especial stimulus. Either with or without a direct effect on the thermogenic centers, the excessive metabolic activity is liable to increase the body heat as well as to increase the 
amount of waste products. The effect on the circulatory system is equally striking; this consists of increased cardiac force and vasoconstriction, as shown in a rise of blood pressure. In the frank invasion there is not only a suddenness of onset of symptoms, but also great severity of symptoms. Internal rhus poisoning may be ushered in by some special phenomena, such as nausea and vomiting, followed by convulsions when the poison acts on the central nervous system. Children are more likely to show the latter effects than adults.

Effects are noted in several parts of the body:

Abdominal Area.-This shows distinct congestion. In the gastrointestinal tract increased peristalsis and diarrhea may be caused. Nausea is common. Intense congestion of the kidneys may cause a diminished output of urine, while slight congestion may somewhat increase the amount.

Pulmonary Area.-This area likewise is congested. Dyspnea is induced by nervous influences and perhaps by a reduction in the air space of the lungs due to congestion. A burning in the throat and a dry hoarse cough may occur.

Cerebral Area.-This area is so closely associated with the large vascular trunks that it shares in the congestion. A feeling of fulness and headache, of greater or less severity, is likely to develop.

The pupils are dilated. The face is usually flushed.

Stage of Acme.-This is in reality but a continuation of the last stage, and is not clearly differentiated from it. The lesions of this period are dependent on congestion, increased metabolism and degenerative changes. Naturally, extension of an inflammatory process may occur by continuity of structure. For instance, in a case of rhus proctitis and vulvitis (Dunmire, ${ }^{10} 1881$ ), peritonitis developed with "great pain and tenderness over the bowels, particularly on the left side, which afterward extended over the abdomen. The slightest pressure would produce pain." At the beginning of the stage of acme, stimulation of the functions occurs, together with congestion and febrile disturbances.

Amphibolic Stage.-This is the sequel of the preceding stage, and is not clearly differentiated from it. It is the wavering stage, for at this time the symptoms are often changeable, and there may be a sudden rise or fall of temperature. If, at this time, the protective powers of the body are sufficient to combat successfully the action of the poison, a reduction of temperature will occur and the disease will decline. Conversely, if the poison proves to be the stronger, the patient finally succumbs to the process. Only one death is recorded

10. Dunmire, J. B.: A Case of Proctitis and Peritonitis from Rhus Poisoning of the Buttocks, Philadelphia Med. Times 12:636, 1881-1882. 
from internal rhus poisoning. A patient suffering from rhus dermatitis chewed some Rhus toxicodendron leaves to produce immunity; he died two days later (Alumbaugh, 1903). If death does not take place in this stage, it is followed by the stage of decline.

Stage of Decline.-In this stage the symptoms which are directly due to the poison disappear, while those incident to the degeneration, inflammatory and metabolic disturbances may persist.

Stage of Convalescence.-The disease itself has now disappeared, but this stage represents the attempt at restitution of the body structures. The length of this period and the ability of the system to recover completely from the effects of the disease are dependent on age, nutrition, sanitary surroundings and other conditions. Other diseases may develop during this period due to depression of vitality, but I have found no record of sequelae or relapses that have occurred in persons poisoned internally by rhus. 